\title{
Comparative Study of the Shape Dependant Electrocatalytic Activity of Platinum Multipods, Discs and Hexagons: Applications for Fuel Cells
}

\author{
Mahima Subhramannia, Kannan Ramaiyan, and Vijayamohanan K. Pillai* \\ SUPPORTING INFORMATION
}

\section{Figure 1}
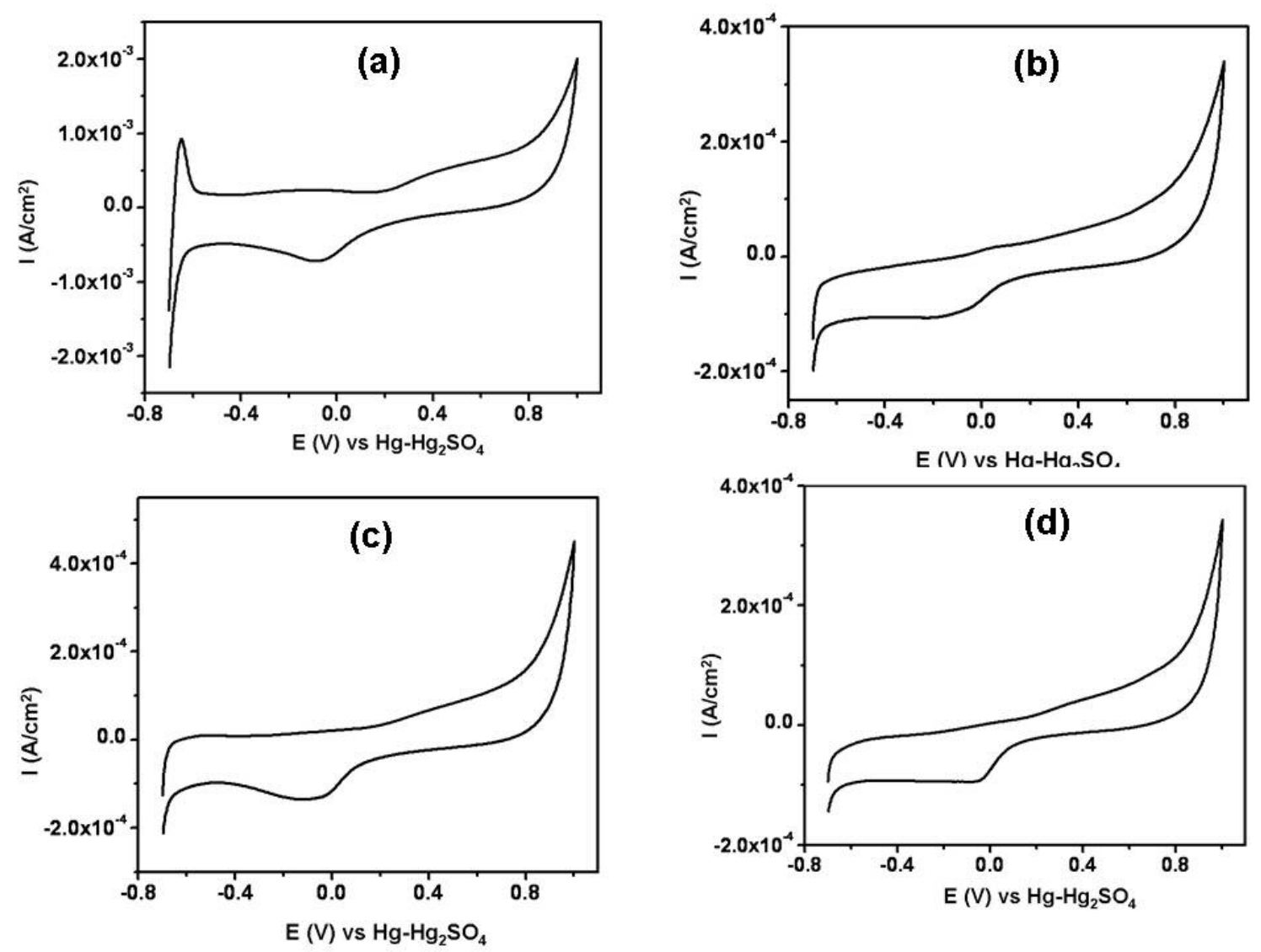

Figure 1. Cyclic voltammograms of (a) Pt/C, (b) Pt/C-multipod, (c) Pt/C-disc and Pt/Chexagon in $0.5 \mathrm{M} \mathrm{H}_{2} \mathrm{SO}_{4}$ at a scan rate of $20 \mathrm{mV} / \mathrm{s}$. 
Figure 2

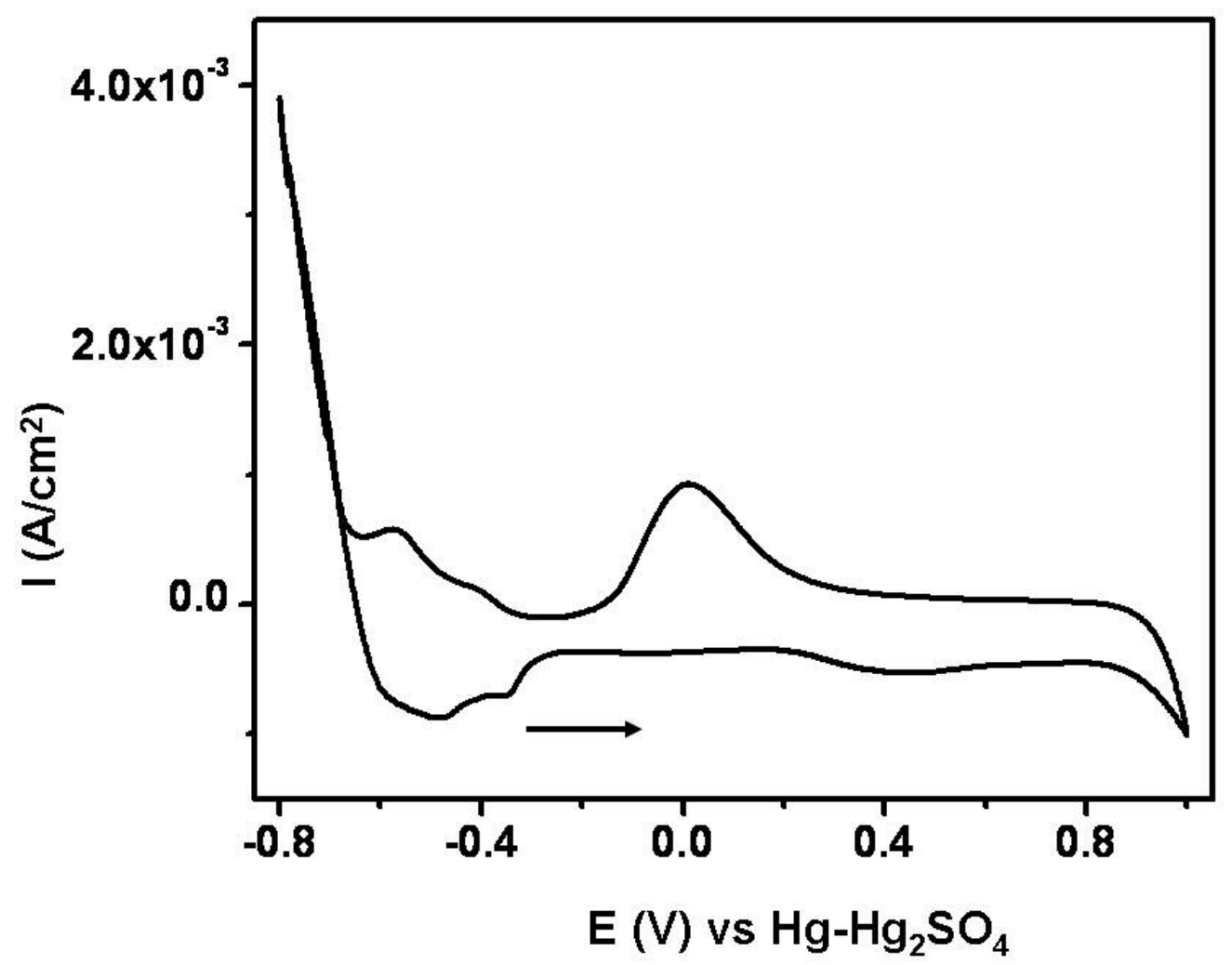

Figure 2. Cyclic voltammetric response of Pt-multipods recorded in $0.5 \mathrm{M} \mathrm{H}_{2} \mathrm{SO}_{4}$ at a scan rate of $20 \mathrm{mV} / \mathrm{s}$; the voltammogram clearly shows the peaks corresponding to hydrogen adsorption/desorption process. 


\section{Figure 3}

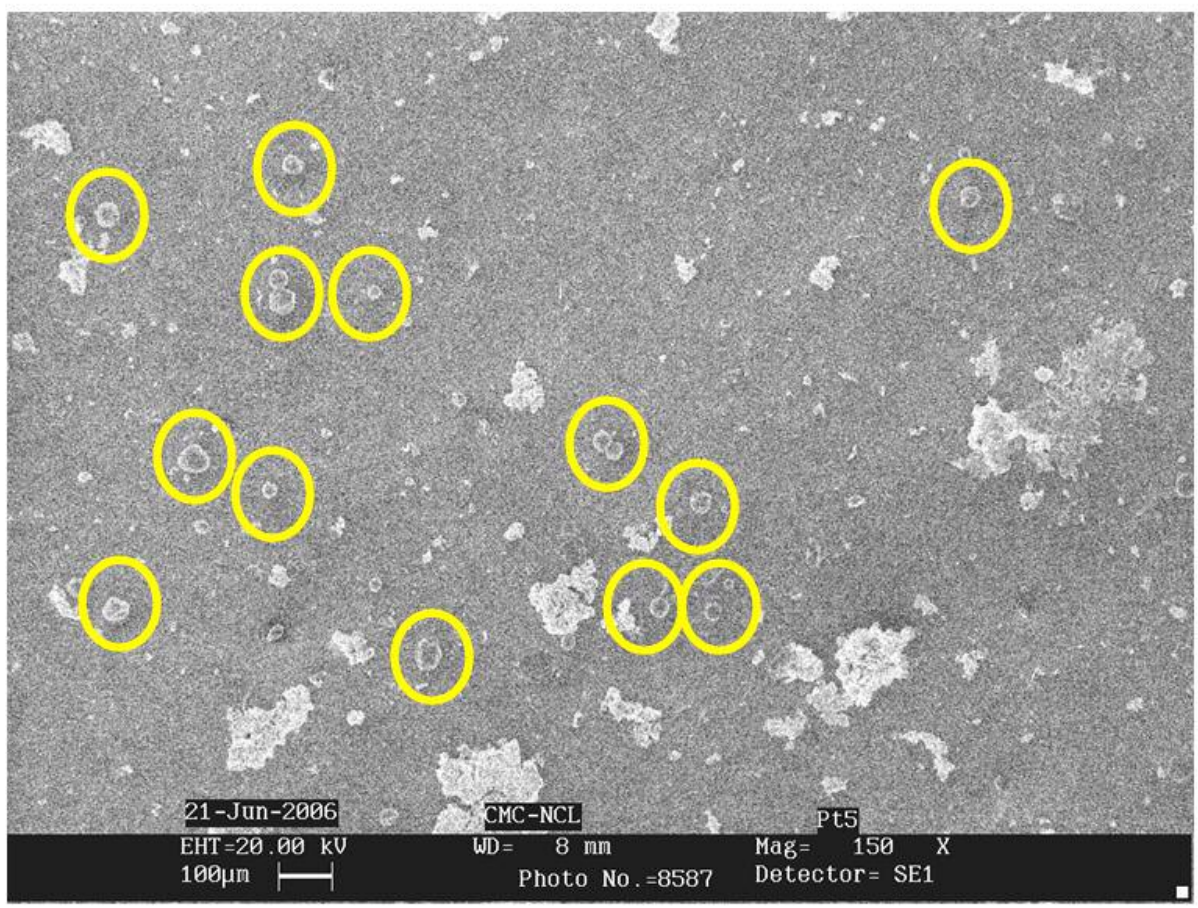

Figure 3. SEM image of disc shaped platinum mesostructures; the image reveals that the majority of the mesostructure exists separately (marked by yellow circles), while multiple structures are present in very few numbers. 


\section{Figure 4}

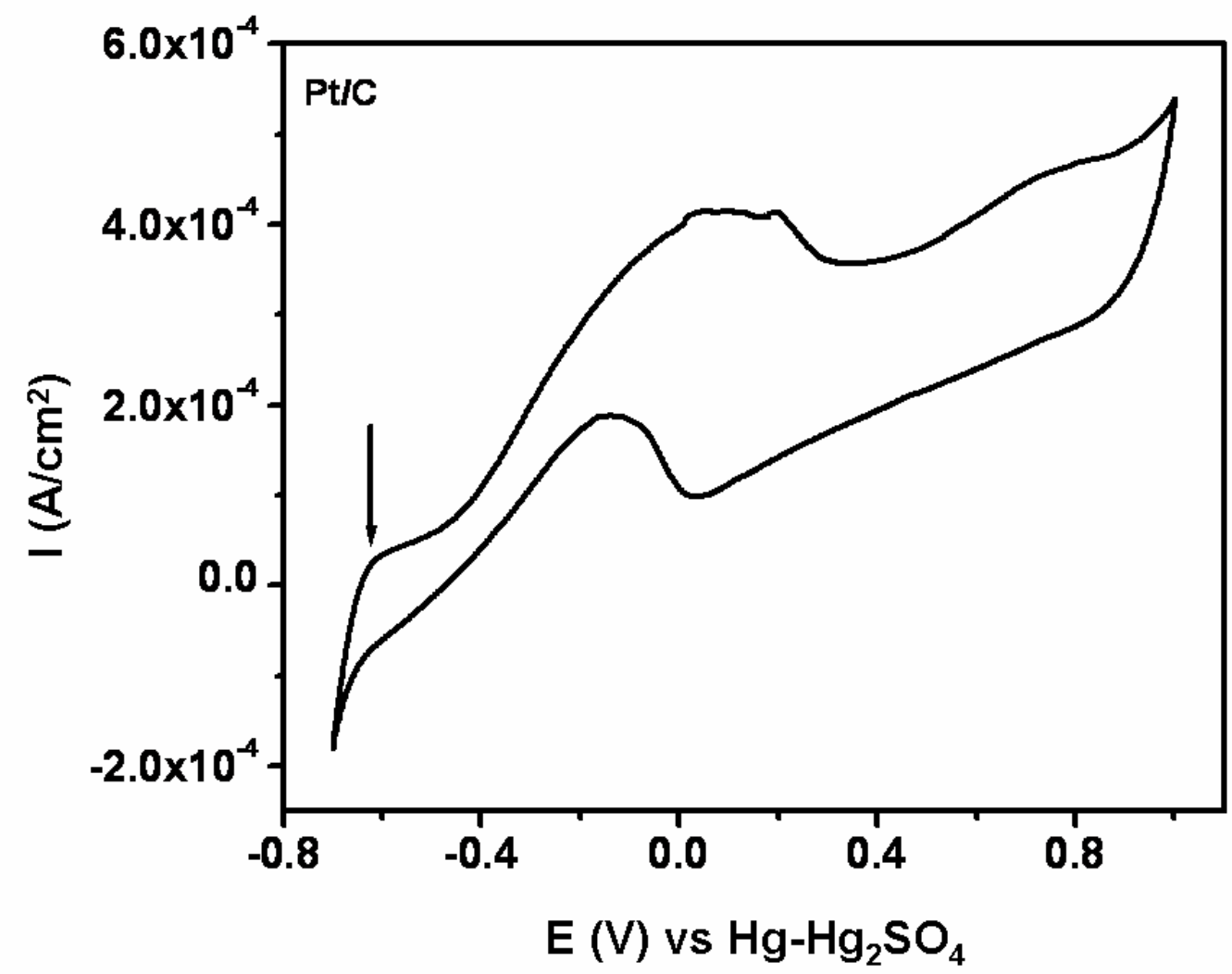

Figure 4. Cyclic voltammetric response of $\mathrm{Pt} / \mathrm{C}$ recorded at a scan rate of $50 \mathrm{mV} / \mathrm{s}$ in $0.25 \mathrm{M} \mathrm{HCOOH}$ and $0.5 \mathrm{M} \mathrm{H}_{2} \mathrm{SO}_{4}$. The voltammogram has shown separately for showing the small peak corresponding to hydrogen adsorption (marked by an arrow). 
Figure 5
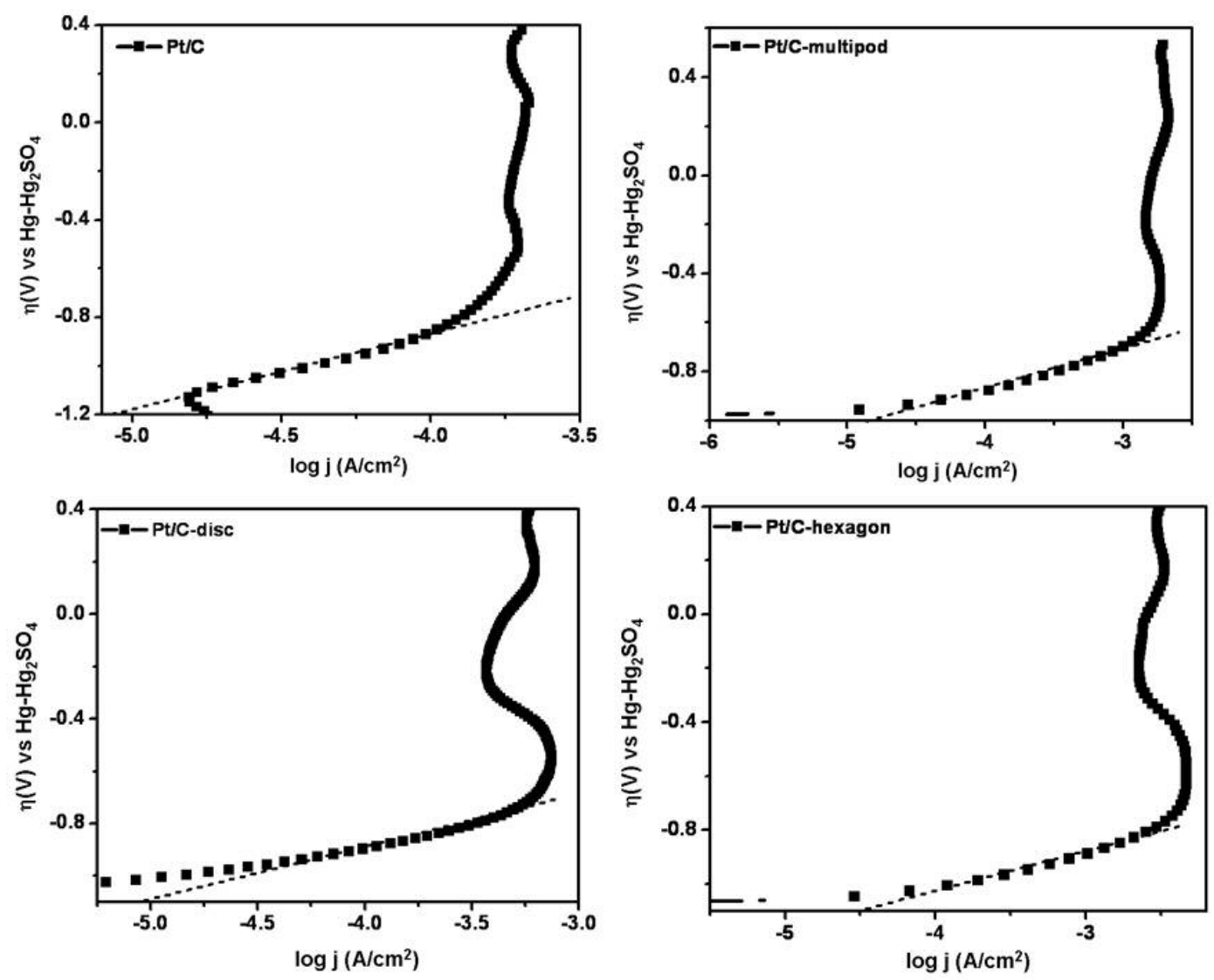

Figure 5. Comparison of the Tafel Plot for the formic acid oxidation on Pt/C-multipod, $\mathrm{Pt} / \mathrm{C}$-disc, Pt/C-hexagon and Pt/C recorded in $0.25 \mathrm{M} \mathrm{HCOOH}$ and $0.5 \mathrm{M} \mathrm{H}_{2} \mathrm{SO}_{4}$. 


\section{Figure 6}
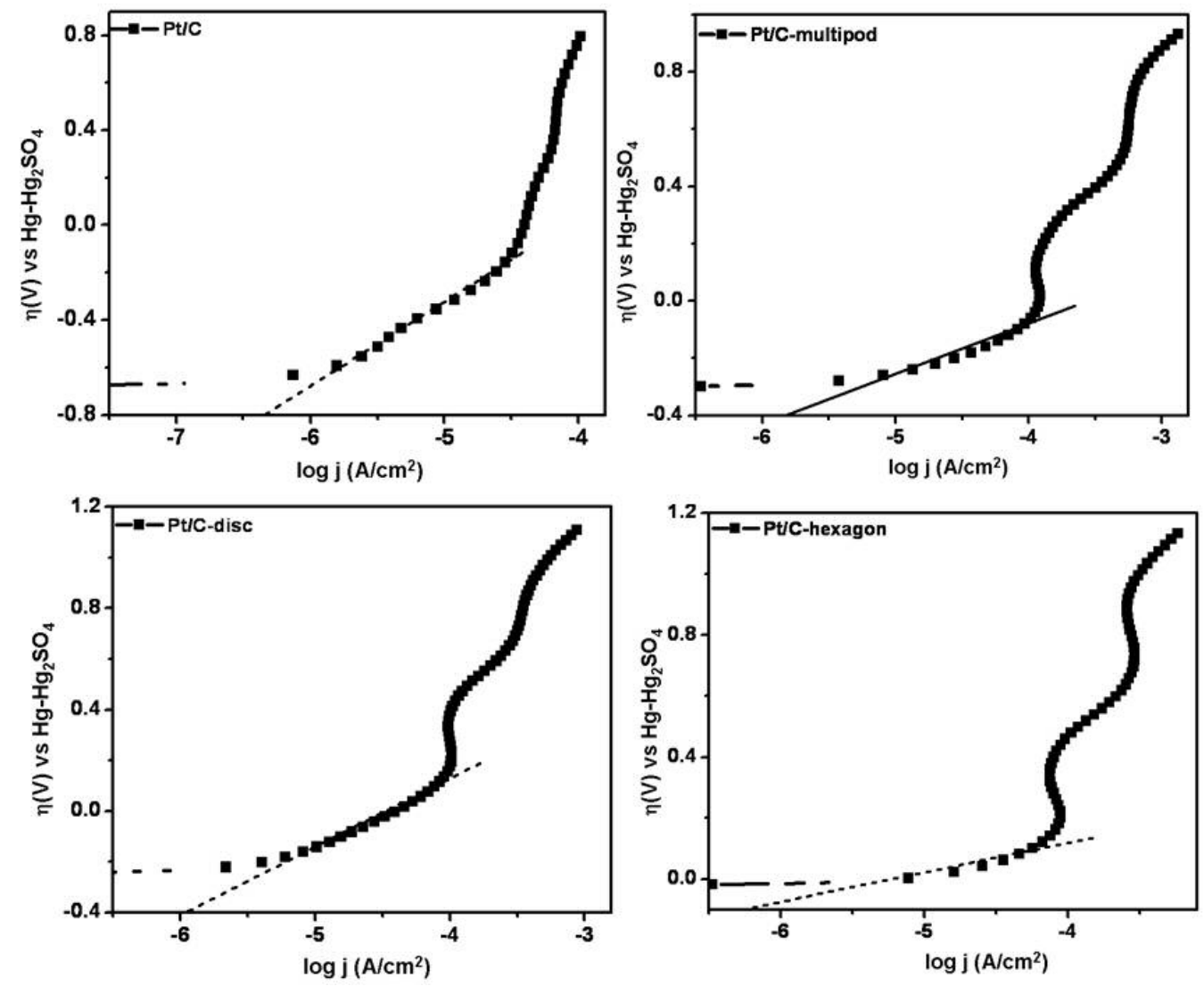

Figure 6. Tafel Plots for the ethanol oxidation on Pt/C-multipod, Pt/C-disc, Pt/C-hexagon and $\mathrm{Pt} / \mathrm{C}$ electrodes recorded in $0.1 \mathrm{M} \mathrm{C}_{2} \mathrm{H}_{5} \mathrm{OH}$ and $0.1 \mathrm{M} \mathrm{HClO}_{4}$. 